\title{
Eloisa Mano e seus Oitenta Anos
}

\author{
A Revista "Polímeros: Ciência e Tecnologia" homenageando a Professora Eloísa B. Mano, que neste mês de outubro \\ faz oitenta anos, apresenta o depoimento de um de seus ex-alunos, o Prof. Carlos A. Hemais, Coordenador do Grupo \\ de Gestão Tecnológica do Instituto de Macromoléculas Professora Eloísa Mano, UFRJ.
}

Para mim, o nome da Professora Eloisa Biasotto Mano se confunde com a história da Ciência e Tecnologia de Polímeros no Brasil, pelos seus mais de 50 anos de trabalhos pioneiros, completamente dedicados em tempo integral ao desenvolvimento dessa área no país. Após uma convivência diária de 36 anos, eu me considero capaz de dar um depoimento sobre a trajetória profissional dessa professora que é um marco nas esferas acadêmicas nacionais.

A Professora Eloisa nasceu no Rio de Janeiro, em 24 de outubro de 1924, onde realizou seus estudos de Graduação, diplomando-se em Química Industrial em 1947 e em Engenharia Química em 1955, pela Escola Nacional de Química da Universidade do Brasil, atual Escola de Química da Universidade Federal do Rio de Janeiro. Já em 1961, obteve sua Livre Docência e grau de Doutor pela Universidade do Brasil e, logo após, concorreu à Cátedra de Química Orgânica da Escola Nacional de Química, sendo empossada como Professor Catedrático em 1962.

Os polímeros estão na vida da Professora Eloisa desde sempre, mas começaram a fazer parte integrante de sua existência a partir do emprego como Químico-Tecnologista do Instituto Nacional de Tecnologia, em 1954, no Laboratório de Borracha e Plásticos. Consciente da necessidade de um aprofundamento científico de seus conhecimentos, a Professora Eloisa foi realizar seu treinamento, em 1956, em Ciência de Polímeros na Universidade de Illinois, EUA, sob a orientação do lendário Professor Carl S. Marvel, um dos pioneiros mundiais no desbravamento dessa ciência. Permaneceu nos laboratórios do Professor Marvel por cerca de um ano e durante esse período desenvolveu uma forte amizade com o mestre, assim como conviveu com diversos alunos do eminente professor, que mais tarde viriam a ocupar, como ela, lugares de destaque no avanço dessa ciência, que começava a se tornar um importante ramo de investigações científicas. Complementou seus estudos em polímeros na Universidade de Birmingham, Inglaterra, sob a orientação do Professor J.C. Bevington, em 1964.

A partir de 1962, como Catedrática de Química Orgânica, introduziu nas aulas de laboratório da Cátedra práticas envolvendo reações de polimerização pela primeira vez no país, começando a despertar em seus alunos o interesse pelos plásticos e borrachas desde os estudos de graduação. Logo depois já orientava alunos de graduação, dos quais gostaria de destacar o Professor David Tabak. Em princípios de 1968, o interesse pelos polímeros já estava se tornando crescente e uma massa crítica começava a se formar em torno da Professora Eloisa. Isto foi fundamental para impulsioná-la a apresentar um projeto ao então BNDE, destinado a criar um grupo de pesquisa único no país, especializado em estudar diversos aspectos das ciências de polímeros. Após os trâmites burocráticos normais, o projeto foi, finalmente, aprovado e, em 28 de outubro de 1968, foi criado o Grupo de Polímeros, com financiamento do BNDE (Projeto BNDE-FUNTEC 51), com duração de quatro anos, que tinha por título "Modificações químicas de polímeros orgânicos". Esse projeto foi renovado pelo BNDE por um período de quase dez anos (Projetos FUNTEC 141 e FUNTEC 170) e foi o responsável pela origem do atual Instituto de Macromoléculas da Universidade Federal do Rio de Janeiro.

Em 1968, o Grupo de Polímeros, ou GP como o chamávamos, era formado pela Professora Eloisa, cercada de seus primeiros 9 alunos de Mestrado, entre os quais estavam a Professora Fernanda Coutinho, bem como de um responsável por toda a parte de gestão administrativofinanceira do projeto, que era eu, na época um jovem estudante iniciando na universidade e que, mais tarde, viria a se tornar mais um professor da casa. O início de muita luta contra a constante falta de produtos e de equipamentos nos laboratórios, bem como de material bibliográfico atualizado, não esmoreceu a fibra da Professora Eloisa, que sempre buscava criar soluções extremamente criativas para contornar situações de grandes dificuldades. Por volta de 1970, foi firmado um convênio entre o CNPq e a National Academy of Sciences (NAS), dos EUA, visando desenvolver diversos aspectos da Química no Brasil. O programa consistia de alocação de um responsável americano e um responsável brasileiro para cada projeto que, em conjunto, tentariam traçar estratégias para o desenvolvimento da área no país. O programa previa, ainda, investimentos de verbas do $\mathrm{CNPq}$ e de um crédito providenciado pela NAS, em dólares, para aquisição de equipamentos e reagentes especiais nos Estados Unidos. Ainda, era prevista a vinda de um pesquisador-junior dos EUA para permanecer em torno de 3 a 4 anos trabalhando no projeto no Brasil. Dentre os projetos agraciados pelo programa estava nossa pesquisa em polímeros, que, sob o comando da Professora Eloisa, encontrou um "sócio" americano na pessoa do Professor Charles G. Overberger, da Universidade de Michigan. O Professor Overberger e a Professora Eloisa já tinham um fator em comum, uma vez que ambos haviam sido alunos do Professor Marvel, e a parceria obteve o maior 
sucesso. O Professor Overberger começou a vir regularmente ao Brasil, pelo menos uma vez por ano, e manteve essa regularidade de visitas, mesmo após o término do projeto, até que sua saúde o impediu de fazer longas viagens, em meados da década de 80. A presença constante do Professor Overberger foi fundamental para o desenvolvimento do grupo, uma vez que, conforme dizia a Professora Eloisa, na época não havia muitos especialistas em polímeros no Brasil e isto contribuía para que as trocas de idéias e conversas sobre pesquisas na área se tornassem muito difíceis. E o Professor Overberger supriu essa lacuna como um grande especialista na área, e se tornou um interlocutor ideal, sempre pronto para ouvir e distribuir ensinamentos sobre as pesquisas que estavam em andamento no grupo.

O grupo cresceu e no início da década de 70 retornaram dos EUA, após conclusão de seus doutoramentos, os Professores Ailton S. Gomes e David Tabak, que passaram a orientar também as pesquisas. Mais tarde se juntou ao grupo o Professor Raul Quijada, que passou também a dividir as responsabilidades da orientação das pesquisas.Em pouco tempo, o grupo, que estava alocado provisoriamente no Departamento de Química Orgânica do Instituto de Química da UFRJ, passou a ter uma produção invejável e sua contribuição, em termos de trabalhos apresentados em congressos e em termos de artigos publicados, além de teses defendidas, era das mais importantes dentro daquele departamento.

Devido ao sólido crescimento do grupo e devido a sua consistente produção científica, a Professora Eloisa percebeu que se não se tornassem independentes, não teriam mais condições de crescer e se consolidar como centro de excelência na condução de pesquisa de alto nível na área de polímeros no Brasil. Havia limitações de verbas, de espaços, de equipamentos,

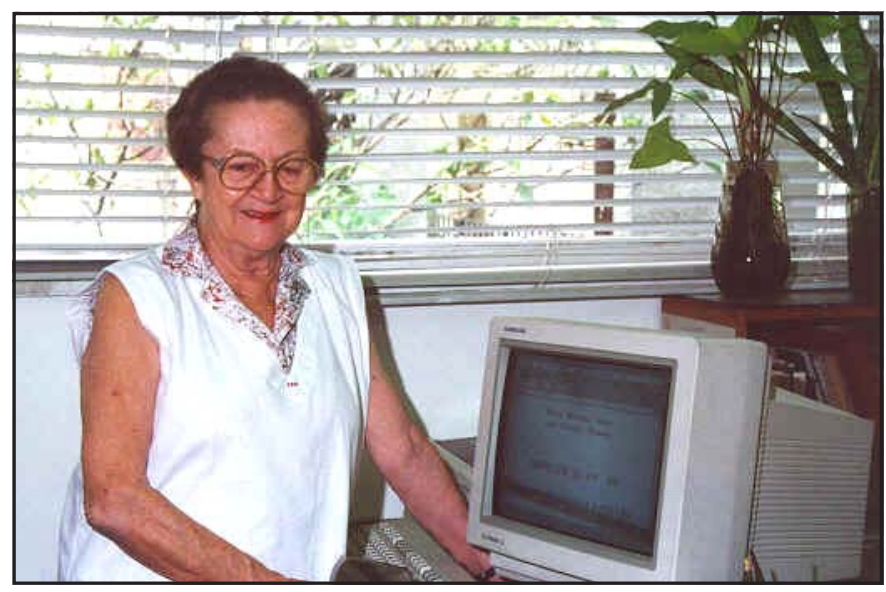

de pesquisas existentes no país. O IMA seria um espaço onde conviveriam químicos, engenheiros químicos, físicos, biólogos, farmacêuticos, engenheiros de materiais, engenheiros mecânicos, economistas e administradores, entre outros, todos voltados para os estudos de polímeros dentro de suas especialidades. Isso foi conseguido, apesar de algumas limitações decorrentes da falta de pessoal em todas as áreas desejáveis, e hoje no IMA pesquisadores de diversas formações pesquisam o estado da arte da ciência e tecnologia de polímeros, bem como aspectos do mercado de polímeros, transferência de tecnologia na área, organização de laboratórios de P\&D em polímeros e patentes sobre polímeros, sendo estes últimos aspectos desenvolvidos pelo Grupo de Gestão Tecnológica, que coordeno na instituição. Dentro desse espírito de multidisciplinaridade, em 1971, o então GP teve seu curso de pós-graduação (Mestrado e Doutorado) em "Ciência e Tecnologia de Polímeros" reconhecido pela alta direção da UFRJ, que passou a se constituir em mais uma das especialidades oficialmente oferecidas pela universidade.

Tornado independente o grupo de pesquisa, criou-se um fato novo: onde alojá-lo? A Professora Eloisa, então, apresentou um projeto à FINEP, com longa exposição de motivos, demonstrando a importância do empreendimento e enfatizando a necessidade de se construir um prédio para abrigar a nova unidade da UFRJ, que já nascia com respaldo internacional e produção científico-tecnológica crescente. Nessa nova luta, foi importante o apoio recebido de renomados pesquisadores estrangeiros, dentre os quais destacamos o Professor Charles Overberger, da Universidade de Michigan, EUA, o Professor Patrick Meares, da Universidade de Aberdeen, Reino Unido, e o Professor Ernst Klesper, da Universidade de Aachen, Alemanha, que foram contatados para, juntamente aliadas às restrições de diversas ordens que constrangiam o normal funcionamento do grupo de pesquisa. Foi então tomada a decisão de iniciar um projeto de transformar aquele grupo de pesquisa em um instituto autônomo, multidisciplinar, totalmente voltado para estudos de polímeros, nos moldes de institutos existentes nas principais universidades americanas e européias. A visão da Professora Eloisa, que parecia originária de um sonho distante, foi-se tornando realidade e, após severas lutas, exposições de motivos, encontros, reuniões e muita discussão política foi, finalmente, conseguida a aprovação, pela UFRJ, da criação do Núcleo de Macromoléculas, em 1972, com existência provisória, que veio a se transformar no Instituto de Macromoléculas - IMA, em 1977.

A multidisciplinaridade imaginada pela Professora Eloisa fazia com que o IMA se distinguisse de qualquer outro grupo com a Professora Eloisa, elaborarem o Plano-Diretor do Instituto, contendo as principais metas a serem alcançadas a longo termo. O que somos? Onde queremos chegar? O que deveremos fazer para chegarmos onde queremos? Quais são nossos pontos fortes? E os fracos? Que tamanho queremos ter? Quais são nossas oportunidades e o que pode nos ameaçar? Respondidas essas perguntas pela Professora Eloisa, apoiada nos consultores internacionais, foi concluído o Plano-Diretor, que serviu de esteio para os pedidos de verba à FINEP para a construção do prédio do IMA, em terrenos da Cidade Universitária da Ilha do Fundão, Rio de Janeiro. Depois de idas e vindas, corte de verbas, renovações de projetos, trâmites burocráticos longuíssimos, foi, finalmente, o prédio préinaugurado em novembro de 1978, com a realização do I SEMPOL Brasil-Estados Unidos e, finalmente, em meados 
de 1979, o IMA passou a funcionar, inteiramente, nas novas instalações, que ainda não estavam totalmente acabadas - o que só foi ocorrer muitos anos depois, devido a pouca verba conseguida para as obras.

Em início da década de 70, o grupo já estava sendo consolidado, mas precisava de um reconhecimento em nível internacional, que respaldasse as linhas de pesquisa em andamento na instituição e tornasse possível a troca de idéias com os maiores especialistas do mundo inteiro. Como era praticamente impossível fazer com que todos os membros do grupo tivessem um treinamento nos melhores centros de pesquisa estrangeiros, a Professora Eloisa optou por desenvolver um projeto de reuniões internacionais periódicas, trazendo pesquisadores de diversos centros internacionais ao Brasil, de forma a torná-los disponíveis para um programa de intensa troca de idéias com nossos professores e pesquisadores. Dessa forma, a Professora Eloisa, após uma acirrada batalha, conseguiu trazer para o Rio de Janeiro a realização do IUPAC International Symposium on Macromolecules, em 1974, congregando mais de 700 participantes, dos quais mais de 100 estrangeiros, oriundos de 35 países. Isso foi o primeiro passo de um programa que envolveu, a partir de 1978, encontros bianuais com pesquisadores de um determinado país, denominados "SEMPOL" (Seminários de Polímeros). Esses encontros se estenderam por dez anos e foram realizados com pesquisadores dos Estados Unidos (I SEMPOL), Argentina, Alemanha, Japão, Chile, e França. Os SEMPOLs trouxeram para o IMA a visibilidade internacional tão necessária, além do estreitamento das relações entre nossos pesquisadores e os mais importantes pesquisadores da área de polímeros naqueles países. Pode-se contabilizar como frutos desses encontros teses realizadas em orientação conjunta, convênios internacionais de pesquisa, que se estenderam por muitos anos, e a vinda de professor estrangeiro para trabalhar no IMA. Neste caso falo do Professor Chiaki Azuma, do Japão, que permaneceu no grupo por cerca de três anos orientando pesquisa e, ao retornar ao seu país, continuou a colaborar com o IMA, através de orientação conjunta de teses e visitas ao IMA a cada dois anos.

Todas essas vitórias foram frutos de muita determinação e muita luta da Professora Eloisa, com todo o apoio do grupo de pesquisas que liderava. Nos momentos de batalha, a presença de uma liderança carismática e muito forte fez a diferença na vida de um grupo de pesquisas que teve a pretensão de se tornar um instituto autônomo, contra a vontade de muitos interesses universitários, que viam ameaças em vez de oportunidades. Hoje o IMA é o único instituto da América Latina totalmente voltado para o estudo de polímeros, em âmbito multidisciplinar.

A Professora Eloisa, fundadora do Grupo de Polímeros, foi diretora do NUMA e depois do IMA, desde sua criação, em 1972, até 1994, quando, por razão de aposentadoria compulsória, a mestra deixou a direção para se tornar Professor Emérito da UFRJ, honraria outorgada a não muitos pesqui- sadores, em reconhecimento aos seus trabalhos feitos em prol do desenvolvimento da ciência e da tecnologia de polímeros. Também, por ocasião da aposentadoria da Professora Eloisa, a partir de uma iniciativa do corpo docente e administrativo do IMA, o Conselho Universitário da UFRJ concordou com a mudança do nome da instituição para Instituto de Macromoléculas Professora Eloisa Mano. Ainda, nessa ocasião, a revista Polymer Bulletin (EUA) lançou um número especial, totalmente dedicado à Professora Eloisa Biasotto Mano, por ocasião de seu $70^{\circ}$ aniversário (vol 34, nº 5/6, 1995).

A aposentadoria não mudou a rotina da experiente mestra, que nunca deixa de vir diariamente ao IMA e de participar ativamente da vida da instituição. Desde 1995, a Professora Eloisa decidiu sedimentar o seu vasto conhecimento, e, a partir daí começou um projeto de escrever uma média de um livro por ano, estando, no momento, com três obras sendo escritas simultaneamente. Assim, já passam de 17 os livros escritos pela mestra, que, também, não negligencia suas atividades de orientadora de teses e autora ou co-autora de artigos científicos, que são publicados nacional e internacionalmente. Hoje a Professora Eloisa acumula uma bagagem de mais de 200 trabalhos publicados em periódicos, mais de 300 comunicações apresentadas em congressos, é detentora de 6 patentes de invenção, além de ter orientado mais de meia centena de teses de Mestrado e de Doutorado.

Detentora de diversos prêmios nacionais e internacionais, em 2000, a Professora Eloisa foi agraciada pelo Presidente da República Fernando Henrique Cardoso com a Grã-Cruz da Ordem Nacional do Mérito Científico, área de Química, o que deixou a comunidade do IMA muito orgulhosa. Além disso, em maio de 2003, a Associação Brasileira de Polímeros criou o Prêmio Professora Eloisa Mano para o melhor trabalho na área de polímeros.



Seus ex-alunos na Escola Nacional de Química, na Escola de Química da UFRJ, no Instituto de Química da UFRJ ou no IMA são incontáveis e muitos têm ocupado lugar de destaque na Indústria Petroquímica Brasileira, tais como Otto Perrone (ex-Presidente da Norquisa), Roberto Villa (ex-Presidente da Rio Polímeros), Amilcar Pereira da Silva (ex-Diretor da Petroquisa), Luiz Carlos Cunha Lima (ex-Diretor do INPI). 
Gostaria, ainda, de lembrar as várias iniciativas tomadas pela Professora Eloisa para congregar a comunidade do IMA socialmente. Ficaram famosas suas Festas de Natal, que, durante muitos anos, traziam ao IMA as famílias de todos os membros da instituição, desde os professores aos alunos e funcionários técnicos e administrativos. A mestra participava pessoalmente dos arranjos dessas festas, as quais gostava de organizar nos mínimos detalhes, semanas a fio. Essas festas deram uma proximidade muito grande entre os elementos constituintes da instituição, fazendo-os reforçar o espírito de corpo, tão enfatizado pela querida professora. Muito famosas também ficaram as Festas Juninas que organizava no terreno em frente ao prédio, visando, além do congraçamento de todos, cultivar a tradição cultural brasileira das festas típicas do meio do ano. Isso englobava a construção de barracas, os prêmios, as comidas típicas, a música apropriada e as quadrilhas, com direito a noivos e delegados. E também os inúmeros jantares organizados em sua casa, muitas vezes com mais de cem convidados, com pretextos os mais variados para sua realização, desde a homenagem a um professor estrangeiro até a comemoração de um título recebido. E nes- sas ocasiões festivas, sempre foi marcante a colaboração incansável da irmã, Rachel Mano, que trazia sua longa experiência de funcionária graduada do Ministério das Relações Exteriores, e colocava seu toque de finesse e elegância em todas as atividades sociais.

Nesses 36 anos de convivência, considero-me ainda hoje aprendendo coisas novas a cada dia com a experiente mestra. Desde o primeiro contato, fui surpreendido pela Professora Eloisa. Quando fui convidado por ela para trabalhar no grupo de pesquisa que estava se formando, era então um jovem universitário, inexperiente profissionalmente, e disse-lhe com a maior franqueza: "eu não tenho qualquer experiência no serviço, mas vou tentar". E ela me respondeu: "eu também não tenho, vamos aprender juntos!"

Essa é pois a Professora Eloisa Mano, que este ano, em sua plenitude intelectual, em seu inteiro vigor profissional, com muitos planos a realizar pela frente, completa seus oitenta anos, e merece um número especial da revista Polímeros: Ciência e Tecnologia. Parabéns a Professora Eloisa e parabéns a revista Polímeros pela iniciativa de realizar esta justa homenagem.

Prof. Carlos A Hemais, Coordenador do Grupo de Gestão Tecnológica, IMA/UFRJ.

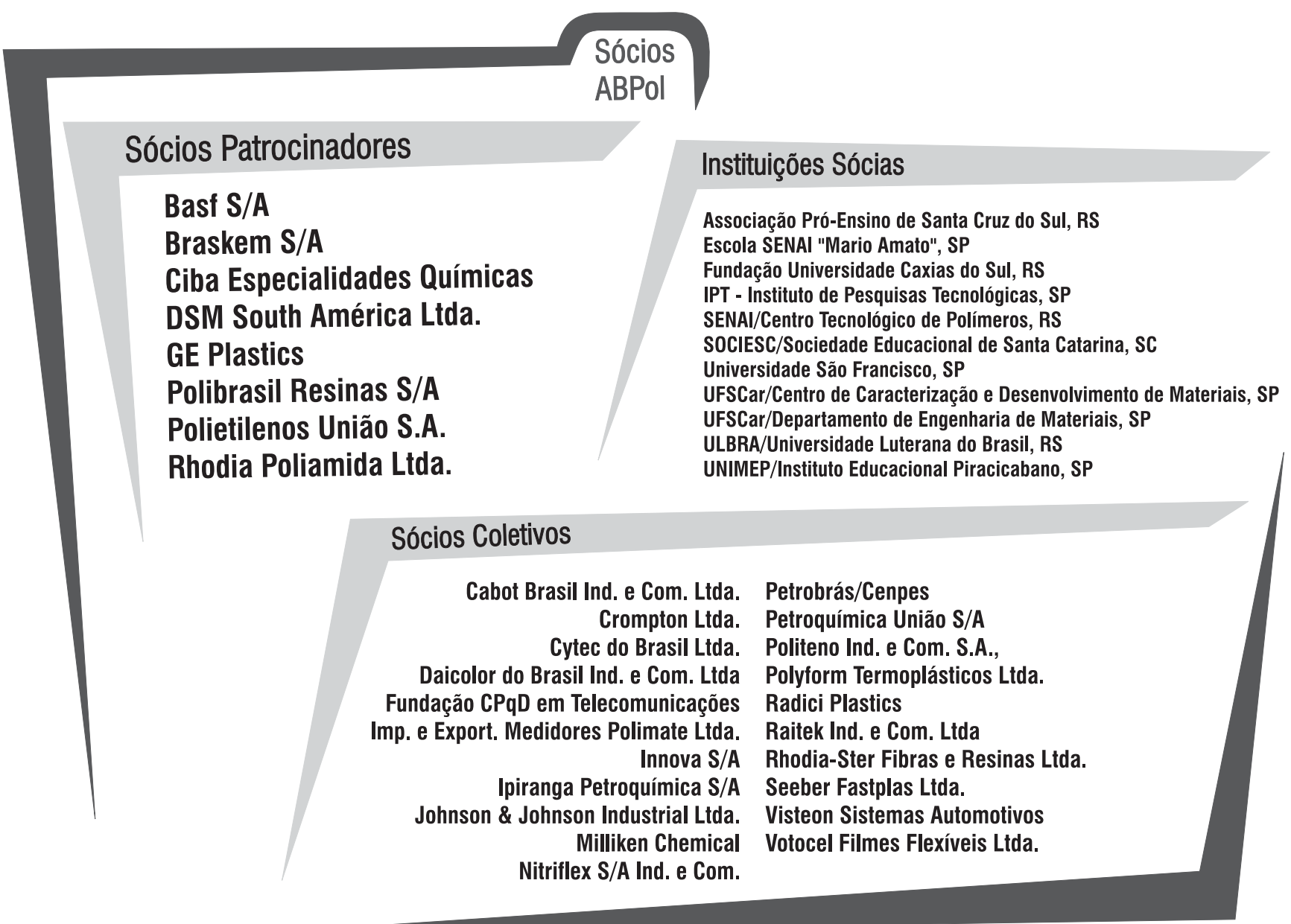

